\title{
Heavy shoulder strengthening exercise in people with hypermobility spectrum disorder (HSD) and long-lasting shoulder symptoms: a feasibility study
}

Behnam Liaghat ${ }^{1 *}$ (D) Søren T. Skou ${ }^{1,2}$, Uffe Jørgensen ${ }^{3}$, Jens Sondergaard ${ }^{4}$, Karen Søgaard ${ }^{5,6}$ and Birgit Juul-Kristensen ${ }^{1}$

\begin{abstract}
Background: People with hypermobility spectrum disorder (HSD) are in great risk of experiencing shoulder symptoms, but evidence for treatment is sparse. Therefore, the objective was to evaluate the feasibility of 16-week shoulder strengthening programme for improving shoulder strength and function in people with HSD and shoulder symptoms for more than 3 months to inform a future randomised controlled trial (RCT).

Methods: Twelve participants (11 females, $39.3 \pm 13.9$ years) with HSD and shoulder instability and/or pain for more than 3 months underwent a 16-week heavy shoulder strengthening exercise programme three times weekly using exercises targeting scapular and rotator cuff muscles. Primary outcomes were pre-defined research progression criteria including recruitment rate (acceptable, 6 participants/month), assessment duration (acceptable: $<120$ min), participant retention (acceptable: > 80\% complete intervention), training adherence (acceptable: $>75 \%$ adhere to > 36 training sessions) and adverse events (acceptable: minor events with no participants discontinuing the study), besides participant and physiotherapist feedback. Secondary treatment outcomes were assessed using the Western Ontario Shoulder Instability Index (WOSI, 0-2100 better to worse), self-reported pain, kinesiophobia and fatigue, isometric shoulder strength, besides clinical tests for instability, hypermobility, laxity, and proprioception.

Results: Recruitment rate was 5.6/month, assessment duration (mean \pm SD) $105 \pm 9$ min, retention 100\%, adherence $83 \%$, and four participants experienced short-lasting soreness or pain. Participant feedback was positive, and physiotherapists found the intervention relevant and applicable to the population. The WOSI total score showed an improvement by 51\% (mean \pm SD, points: baseline $1037 \pm 215$; Follow up $509 \pm 365$; mean change $(95 \% \mathrm{Cl}),-528(-738,-318))$, and participants reported reduced pain, kinesiophobia and fatigue. Shoulder strength measurements improved by $28-31 \%$ (mean change $(95 \% \mathrm{Cl})$, Nm/kg: scaption 0.51 (0.23, 0.78); internal rotation $1.32(0.70,1.95)$ and external rotation $0.89(0.37,1.40))$, and clinical tests indicated decreased shoulder laxity/ instability.

\footnotetext{
* Correspondence: bliaghat@health.sdu.dk

${ }^{1}$ Research Unit for Musculoskeletal Function and Physiotherapy, Department of Sports Science and Clinical Biomechanics, University of Southern Denmark, Odense, Denmark

Full list of author information is available at the end of the article
}

(c) The Author(s). 2020 Open Access This article is licensed under a Creative Commons Attribution 4.0 International License, which permits use, sharing, adaptation, distribution and reproduction in any medium or format, as long as you give appropriate credit to the original author(s) and the source, provide a link to the Creative Commons licence, and indicate if changes were made. The images or other third party material in this article are included in the article's Creative Commons licence, unless indicated otherwise in a credit line to the material. If material is not included in the article's Creative Commons licence and your intended use is not permitted by statutory regulation or exceeds the permitted use, you will need to obtain permission directly from the copyright holder. To view a copy of this licence, visit http://creativecommons.org/licenses/by/4.0/ The Creative Commons Public Domain Dedication waiver (http://creativecommons.org/publicdomain/zero/1.0/) applies to the data made available in this article, unless otherwise stated in a credit line to the data. 
(Continued from previous page)

Conclusions: The shoulder strengthening exercise programme was feasible and safe for people with HSD and long-lasting shoulder symptoms. A future RCT, with an improved recruitment strategy, will demonstrate whether the exercise programme is also effective in improving symptoms and muscle-tendon function in this population.

Trial registration: ClinicalTrials.gov: NCT03547570. Registered on May 3, 2018.

Keywords: Hypermobility, Hypermobility spectrum disorder, Shoulder, Strength, WOSI

\section{Background}

Generalised joint hypermobility (GJH), characterised by the capability to move the joints beyond normal range of motion [1], has an estimated prevalence of $30 \%$ in the Danish population, but the prevalence varies between $2 \%$ and $57 \%$ in adults depending on the diagnostic criteria used and population investigated [1-3].

Approximately $80 \%$ of people with $\mathrm{GJH}$ experience shoulder symptoms [4-6], and most display strength deficits, altered muscle activity [4, 7], instability due to repeated episodes of joint subluxations, functional deficits, and chronic pain [8-10]. GJH with such symptoms has recently been classified as hypermobility spectrum disorder (HSD) [11]. Several studies have found that people with HSD combined with shoulder symptoms report lower health-related quality of life than healthy controls $[5,6,12]$.

Evidence for clinical management of people with HSD combined with shoulder symptoms is limited [13, 14]. Current evidence, based primarily on uncontrolled studies without long-term follow up and poorly described exercise programmes, demonstrates that people with HSD and shoulder symptoms including multidirectional instability benefit significantly from exercise-based treatment with the aim of targeting active elements which are involved in shoulder stability [4, 15-18]. However, most studies fall short of recommending specific types of exercise as superior to general advice [15-17]. Current guidelines recommend stability exercises and advice about joint protection, but evidence for these recommendations is sparse and based on theoretical ideas rather than being scientifically proven [13, 14]. From a physiological perspective, mechanical loading (e.g. heavy strengthening exercise) is known to increase muscle strength and tendon stiffness $[19,20]$, which seems to be a relevant treatment of HSD $[21,22]$. However, the feasibility, safety, and effectiveness of heavy strengthening exercises in adults with HSD and shoulder symptoms are uninvestigated.

Therefore, the objective was to evaluate the feasibility of a 16-week progressive heavy shoulder strengthening exercise programme in people with HSD and long-lasting shoulder symptoms for more than 3 months to inform a future randomised controlled trial (RCT). Primary outcomes included pre-defined research progression criteria (participant recruitment and retention, duration of the collection of outcome measures, adherence to the exercise programme, and adverse events), besides participant and physiotherapist feedback, and a range of secondary selfreported outcomes and objective measurements.

\section{Methods}

Study design

This feasibility study was designed to evaluate research progression criteria in preparation of a definitive parallel-group RCT. However, because most of these criteria except the recruitment rate were related to the experimental intervention alone, no comparator or randomisation was used. No blinding was applied in follow-up measurements, but the principal investigator, who was also the outcome assessor, did not have access to baseline values until after completing follow-up assessments. Reporting was conducted according to the CONSORT statement extension to randomised pilot and feasibility trials [23] (Additional file 1), with research progression criteria based on a traffic light system of green (continue without changes), amber (apply changes to improve study design) and red (no RCT unless major changes are applied) [24]. The study complied with principles of the Declaration of Helsinki, was approved by the Regional Committees on Health Research Ethics for Southern Denmark (S-20170066), and prospectively registered in clinicaltrials.gov (NCT03547570).

\section{Participants}

Males and females aged between 18 and 65 years were included provided they had generalised HSD (G-HSD) using the Beighton score cut off $\geq 5 / 9$ for females up to the age of 50 years and $\geq 4 / 9$ for females above 50 years and males [25], or historical HSD (H-HSD) if the Beighton score was 1 point below the age and sexspecific cutoffs, and the 5-part questionnaire (5PQ) was positive ( $\geq 2 / 5$ positive items), plus having minimum one secondary symptomatic musculoskeletal manifestation $[1,11,25]$. Musculoskeletal manifestations were defined as self-reported (i) shoulder pain for minimum 3 months, (ii) recurrent dislocations or (iii) atraumatic instability. Atraumatic instability was defined as a minimum of three atraumatic shoulder dislocations, a history of at least two atraumatic dislocations in two different 
joints (a minimum of one in the shoulder), or medically confirmed atraumatic instability in at least two joints (a minimum of one in the shoulder) [25].

Exclusion criteria were systemic inflammatory rheumatic diseases, connective tissue diseases (e.g. Marfans, Stickler's or Loeys-Dietz syndromes), Ehlers-Danlos syndrome (except hypermobile type), neurological diseases, pregnancy or childbirth and/or shoulder surgery within the past year, referred pain from the cervical spine on reasonable clinical suspicion by either the general practitioner (GP) or physiotherapist, and inability to speak and/or understand Danish.

Participants were recruited from April to July 2018 in primary care by GPs and physiotherapy clinics from the Region of Southern Denmark, who received information about the project and education about how to identify eligible participants. Participants were asked to answer a pre-screening electronic questionnaire including the 5PQ [26] and questions about shoulder symptoms through the web-based Research Electronic Data Capture (REDCap) [27]. The principal investigator contacted potentially eligible participants to schedule a final screening. Participants would then receive a confirmation of their scheduled appointment and detailed project information by email. At a physical meeting, the primary investigator gave oral information and performed physical screening using the Beighton tests. An informed written consent was obtained before enrolment, and the rights of participants were protected. The exercise intervention was performed at a physiotherapy clinic close to the participant's home.

\section{Intervention}

The intervention was standardised and described according to the template for intervention description and replication (TIDieR) checklist [28] (Additional file 2), the Consensus on Exercise Reporting Template (CERT) [29] and included a thorough mechano-biological description as recommended by Toigo and Boutellier [30] (Additional file 3). Participants received 16 weeks of heavy shoulder strengthening exercise programme, supervised by a physiotherapist twice weekly and self-managed once weekly. 5-repetition maximum (RM) strength tests were carried out at first session to estimate $10 \mathrm{RM}$ using Brzycki's formula [31]. Weeks 1-3 were characterised as a familiarisation period with three sets of $50-90 \%$ of 10 RM. Weeks 4-9 included three sets of $10 \mathrm{RM}$, and from Weeks $10-15$, the exercise intensity was four sets of 8 RM $[22,32]$. A tapering period was applied in Week 16 to allow for anabolic response prior to follow-up assessment [32]. The load was increased whenever the participant could complete more than the pre-defined repetitions for all sets with acceptable symptoms below $5 / 10$ on the numerical pain rating scale (NPRS) and good movement quality defined as no glenohumeral subluxation and without producing obvious scapula dyskinesis compared to unloaded movement [33]. The exercise programme included five exercises targeting scapular and rotator cuff muscles (Fig. 1) [34, 35].

Five physiotherapists $(1,3,11,16$, and 18 years of practicing experience) had undergone a 3-h theoretical and practical education programme supported with a manual with detailed exercise instructions and the option to contact the principal investigator with questions. The same physiotherapist supervised the participant throughout the intervention period, and when necessary, another physiotherapist from the same clinic acted as stand-in. In vacation periods, participants were encouraged to self-exercise three times weekly with adjustable dumbbells provided by the project and an exercise manual written in layman's terms.

\section{Outcomes}

The feasibility study used a mixed outcome approach based on primary outcomes including pre-defined research progression criteria (Table 1), qualitative feedback from participants and physiotherapists, and a range of secondary self-reported outcomes and objective measurements to cover most aspects of potential benefits and identify outcomes which were responsive to the intervention. General demographic information was also obtained and included sex, age, weight, height, civil status, educational level, employment status, disease history, and physical activity level (high, moderate, or low) using the short version of International Physical Activity Questionnaire (IPAQ) [46, 47].

\section{Primary outcomes}

Recruitment procedures were evaluated by comparing number of participants at pre-screening with participants eligible for inclusion to identify reasons for exclusion and optimise the eligibility criteria. Recruitment rate was analysed by dividing number of included participants $(n=12)$ by the number of months it took to include them (calculated from study start until the 12th participant was recruited). To evaluate duration of baseline and follow-up assessments, completion was timed, and participants were asked if they found the duration acceptable (yes/no). Participant retention was evaluated by number of participants showing up at 16-week follow up. To evaluate exercise adherence, exercise logs were completed at each session by both the participant (at home) and the physiotherapist (when supervised) covering pain before and after exercise, load and intensity, and use of pain medication. Adherence was calculated by counting number of exercise sessions completed in the exercise log, divided by 48 planned sessions, presented in percentage. 

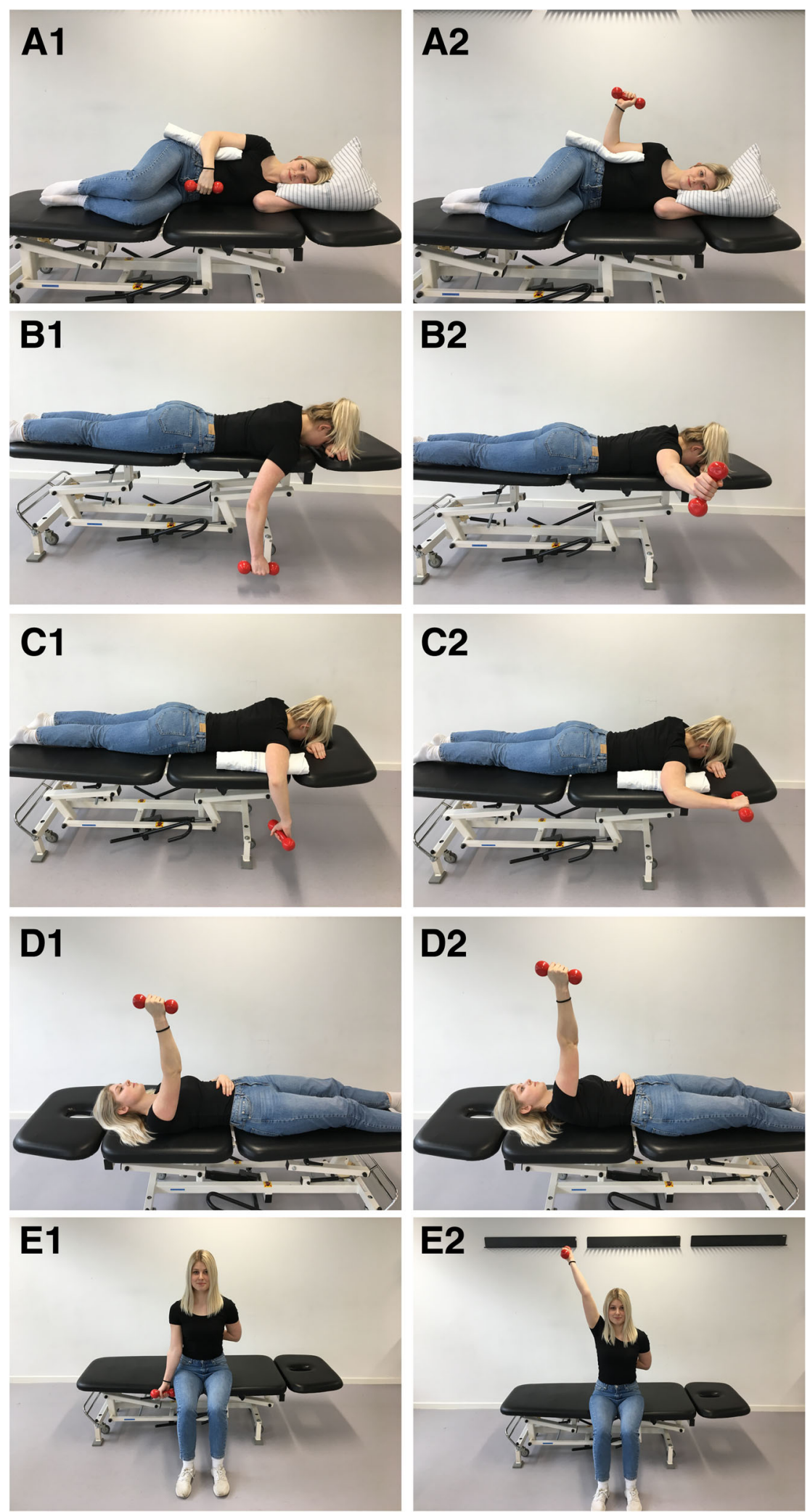

Fig. 1 The exercise programme included five exercises targeting scapular and rotator cuff muscles. A1-A2: sidelying external rotation (ER) in neutral, B1-B2: prone horizontal abduction, C1-C2: prone ER in 90 of shoulder abduction, D1-D2: supine scapular protraction, and E1-E2: seated shoulder elevation in the scapular plane 
Table 1 Research progression criteria for continuing to the definitive randomised controlled trial

\begin{tabular}{|c|c|c|c|}
\hline Outcome & Green & Amber & Red \\
\hline $\begin{array}{l}\text { Participant } \\
\text { recruitment }\end{array}$ & $\begin{array}{l}\text { Inclusion rate of one participant per general } \\
\text { practitioner or physiotherapist every month } \\
\text { (approximately } n=6-8 / \text { month) }\end{array}$ & $\begin{array}{l}(n<6 \text { after first month). If recruitment rate falls } \\
\text { behind, screening logs and reasons for exclusion will } \\
\text { be explored after the first month to adjust eligibility } \\
\text { criteria. }\end{array}$ & $\begin{array}{l}\text { No recruitment after } 2 \\
\text { months }\end{array}$ \\
\hline $\begin{array}{l}\text { Completion of } \\
\text { the outcome } \\
\text { measures }\end{array}$ & $\begin{array}{l}\text { Mean }<120 \text { min to complete all objective } \\
\text { outcome measures, and that at least } 67 \% \text { of } \\
\text { participants found the duration acceptable. }\end{array}$ & $\begin{array}{l}\text { Between } 121 \text { and } 150 \text { min, or only } 50-66 \% \text { of } \\
\text { participants found the duration acceptable. }\end{array}$ & $\begin{array}{l}>150 \text { min or }<50 \% \text { of } \\
\text { participants found the } \\
\text { duration acceptable }\end{array}$ \\
\hline $\begin{array}{l}\text { Participant } \\
\text { retention }\end{array}$ & $\begin{array}{l}10 \text { or more participants show up at 16-week } \\
\text { follow up }\end{array}$ & Only 6-9 participants show up at 16-week follow up. & $\begin{array}{l}\text { Below } 6 \text { participants } \\
\text { show up at } 16 \text {-week } \\
\text { follow up. }\end{array}$ \\
\hline $\begin{array}{l}\text { Adherence to } \\
\text { exercise } \\
\text { intervention }\end{array}$ & $\begin{array}{l}\text { Minimum } 75 \% \text { of participants adhering to at least } \\
75 \% \text { of exercise sessions. }\end{array}$ & $\begin{array}{l}\text { Only } 50-75 \% \text { of participants adhering to } 50-75 \% \text { of } \\
\text { exercise sessions. }\end{array}$ & $\begin{array}{l}<50 \% \text { of participants } \\
\text { adhering to }<50 \% \text { of } \\
\text { exercise sessions }\end{array}$ \\
\hline $\begin{array}{l}\text { Adverse } \\
\text { events }\end{array}$ & $\begin{array}{l}\text { No or minor adverse events with no participants } \\
\text { discontinuing the study }\end{array}$ & $\begin{array}{l}\text { Minor or serious adverse events leading to } 2 \text { or less } \\
\text { participants discontinuing the study }\end{array}$ & $\begin{array}{l}\text { Serious adverse events } \\
\text { leading to }>2 \\
\text { participants } \\
\text { discontinuing the study }\end{array}$ \\
\hline
\end{tabular}

Research progression criteria were based on a traffic light system of green (go), amber (amend) and red (stop) [24]. Results of these research progression criteria were evaluated by the research group, who recommended whether to proceed with the definitive randomised controlled trial, and which amendments that needed to be made before proceeding

Adverse events were registered at every exercise session and at follow up, and furthermore, participants received an electronic questionnaire by email every week with questions about adverse events, pain levels, sickness absence, use of pain medication, and additional healthcare treatment. Minor adverse events covered symptom flare-up, subluxations, and post-exercise fatigue. Serious adverse events were unexpected but covered lifethreatening events, disability, or permanent damage [36]. Based on these research progression criteria, the investigators would evaluate the results and decide which amendments that needed to be made.

\section{Participant and physiotherapist feedback}

Participants were asked to provide feedback at 16-week follow up on a custom-made questionnaire with open questions on acceptability of assessment procedures, previous treatment experience compared with heavy shoulder strengthening exercise, and feedback about the supervised sessions and potential adverse events. Physiotherapist feedback covered whether exercises were applicable to this population and their experience with using the exercise manual, including handling the progression of exercise intensity, and exercise and load modification in case of pain flare-ups or other adverse events. Both participants and physiotherapists were asked to suggest potential improvements for the study design and procedures.

\section{Secondary outcomes}

Self-reported outcomes The most important selfreported outcome (additional file 4) was the electronical version of Western Ontario Stability Index (WOSI), which is a valid, reliable and sensitive assessment for participants with shoulder symptoms associated with instability (0 best score to 2100 worst score) [37]. Other self-reported outcomes included pain (NPRS during past 7 days) (0 no pain, 10 extreme pain) [38]; Checklist of Individual Strength (CIS), subscale fatigue (prolonged fatigue) ( 8 best, 56 worst) [39]; Dartmouth Primary Care Cooperative Research Network/World Organization of National Colleges, Academies and Academic Associations of General Practitioners/Family Physicians (COOP/ WONCA) (functional health status) (6 good functional status, 30 poor functional status) [40, 41]; Tampa Scale of Kinesiophobia-11 (TSK-11) (perceived fear of movement) (11 low, 44 high) [42]; Global Perceived Effectiveness (GPE) (impression of recovery) (- 5 much worse, 5 much better) [43, 44]; and European Quality of life - 5 Dimensions - Three-Level Scale (EQ-5D-3L) (health-related quality of life) (index score: < 0 to 1 (full health), with anchoring of death as 0). In addition, the EQ-5D$3 \mathrm{~L}$ includes the European Quality of life visual analogue scale (EQ-VAS) where the patient's own health 'today' is rated between 0 (worst imaginable health) and 100 (best imaginable health) [45].

Objective outcomes The objective measurements (additional file 5) included seated maximum isometric voluntary contraction of shoulder scaption in $45^{\circ}$, internal rotation (IR), and external rotation (ER) in neutral with hand-held dynamometry (IsoForce Dynometer EVO2; Medical Device Solutions AG) [46, 48]; passive shoulder range of motion using supine ER and IR with the shoulder abducted to $90^{\circ}$ and elbow flexed to $90^{\circ}$, measured with a digital inclinometer (Halo, Halo Medical Devices, Subiaco, Australia) [46, 47]; and shoulder flexion 
proprioception (low range $55^{\circ} \pm 10^{\circ}$, mid-range $90^{\circ} \pm$ $10^{\circ}$, and high range $125^{\circ} \pm 10^{\circ}$ ) [48]. Joint mobility and laxity parameters were assessed using load and shift, sulcus sign, Gagey, apprehension, relocation, release [49], Rotés Qúerol [50], shoulder total rotation test (positive if sum of IR and ER range of motion $>180^{\circ}$ ), and the shoulder flexion test [51].

\section{Sample size}

No sample size calculation was performed, but 12 participants were included based on the rationale for a feasibility study, regulatory considerations and statistical considerations about a precise and representable mean and variance [52].

\section{Data analysis}

Research progression criteria were presented with descriptive statistics. Continuous data was assessed for normality (QQ-plots and histograms) and presented as mean \pm standard deviation when fulfilling assumptions for normality, or as median [interquartile range] or frequency (\%). Participant and physiotherapy feedback from questionnaires were reported descriptively and organised into categories related to recruitment procedures, assessment procedures, exercise intervention, intensity progression, adverse events, and perceived treatment effect for the individual participant. Changes from baseline to follow up on secondary outcomes were assessed using paired $t$ tests with significance level set to $5 \%$. All statistical analyses were performed using Stata (StataCorp. 2019. Stata Statistical Software: Release 16. College Station, TX: StataCorp LLC).

\section{Results}

Twenty-two participants were assessed for eligibility from April 25 to July 11, 2018, and 12 participants (11 females) were included (Fig. 2), aged $39.3 \pm 13.9$ years and with median symptom duration of 36 [IQR, 15-66]

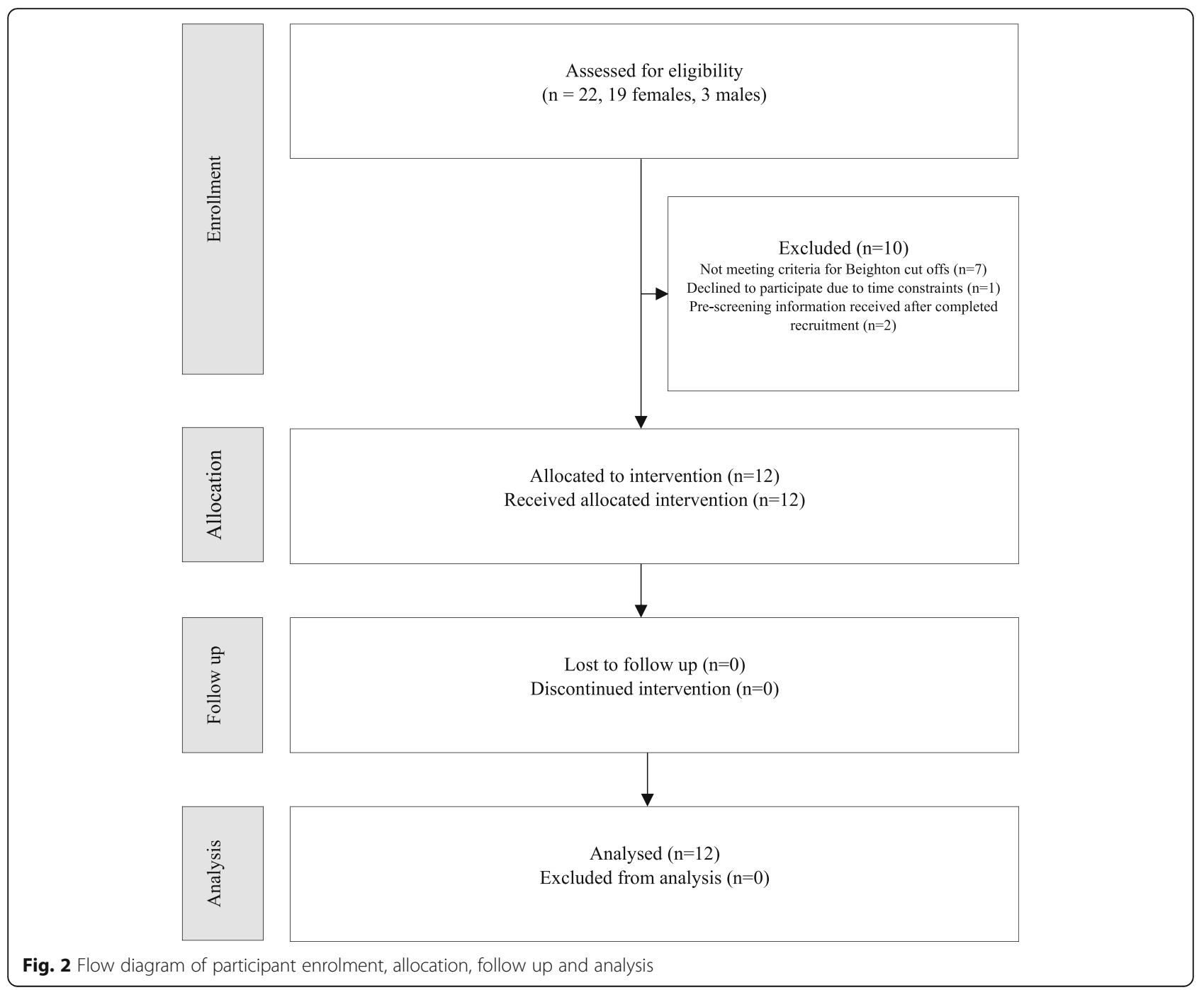


months (Table 2). The main reason for exclusion was not meeting criteria for Beighton cut offs $(n=7)$. All 12 participants received the exercise intervention and were included in the analysis.

\section{Primary outcomes}

Except for recruitment rate at 5.6 participants/month, level of acceptance was met for all other research progression criteria (assessment duration, participant retention, adherence, adverse events) (Table 3). During the first month, seven participants were recruited, meeting criterion for green, while recruitment rate was lower in the following months, presumably because of holidays and summer vacation.

Nine participants had a $100 \%$ completion adherence of the weekly electronic questionnaire, and the remaining three participants had completion adherence of $18.75 \%$, $43.75 \%$ and $87.50 \%$. Four participants reported minor adverse events: short-lasting soreness, ache, and 'stuck' shoulder (twice) (participant 5); headache and general soreness after exercising (participant 7); acceptable soreness (participant 10); and new pain development during handball throws (participant 12).

\section{Participant and physiotherapist feedback}

Participants (75\%) and physiotherapists (100\%) were satisfied with the study design and intervention. None of the participants had been offered heavy shoulder strengthening exercise as treatment for their shoulder symptoms prior to this study, and although some

Table 2 Baseline demographic and clinical characteristics for participants with hypermobility spectrum disorder (HSD) and long-lasting shoulder symptoms $(n=12)$

\begin{tabular}{ll}
\hline Characteristic & \\
\hline Age, years & $39.3 \pm 13.9$ \\
Sex (females/males) & $11 / 1$ \\
Height, cm & $168.0 \pm 7.6$ \\
Weight, kg & $73.8 \pm 13.5$ \\
Hypermobility spectrum disorder (HSD) & \\
$\quad$ Beighton score, 0-9 & $4.5 \pm 1.2$ \\
5PQ, 0-5 & $3.4 \pm 1.1$ \\
$\quad$ Historical HSD, $n$ (\%) & $6(50.0)$ \\
$\quad$ Generalised HSD, $n$ (\%) & $6(50.0)$ \\
Symptom duration, months & $36[15-66]$ \\
Shoulder pain at inclusion, $n$ (\%) & $11(91.7)$ \\
Previous shoulder dislocation, $n$ (\%) & $3(25.0)$ \\
WOSI total score, 0-2100 & $1037 \pm 215$ \\
IPAQ short version (high, moderate, low), $n$ (\%) & $7(58.3), 2$ (16.7), 3 (25.0)
\end{tabular}

Data are presented as mean \pm standard deviation, median [interquartile range], or number (percentage)

5PQ 5-part questionnaire, WOSI Western Ontario Shoulder Instability Index, IPAQ The International Physical Activity Questionnaire participants found the heavy shoulder strengthening exercise programme demanding, they all found it relevant. Although potential challenges were holidays and sickness interfering with the 16-week long intervention, participants were able to find alternative ways to exercise during those situations. Participants reported that intensive supervision regularly was important to ensure exercises were performed correctly, and that exercise progressions were adequately applied. The physiotherapists were satisfied with the 3-h educational course about the intervention and found the exercise programme useful with satisfactory descriptions of exercise progression criteria. Four participants and all physiotherapists requested dumbbells that could be adjusted with lighter weights for precise exercise load progression.

\section{Secondary outcomes Self-reported outcomes}

All participants improved in WOSI total score (on average 51\%) and on all subscales (Fig. 3 and Table 4). Participants reported less pain (46-69\%), decreased kinesiophobia (13\%), and lower levels of fatigue (23\%), and $83 \%$ had positive scores on GPE (participants 3 and 7 had 1 and 0 , respectively). Overall functional status (COOP/WONCA) and general health (EQ-5D-3L) improved with $8 \%$ and $1-10 \%$, respectively.

\section{Objective outcomes}

Improvement in shoulder strength corresponded to 28 $31 \%$, and clinical tests indicated decreased shoulder laxity/ instability (decreased range of motion and more participants with negative shoulder instability/laxity tests except shoulder flexion test and anterior load and shift).

\section{Discussion}

The current study with heavy shoulder strengthening exercise in people with HSD and long-lasting shoulder symptoms more than 3 months is feasible in terms of participant retention, duration of assessments, adherence to the exercise programme, and adverse events, while recruitment rate needs to be optimised in a future RCT. Most self-reported outcomes and objective measurements showed improvements, and only few participants experienced short-lasting soreness or pain flare-ups.

The research progression criteria to inform a future RCT were based on recommendations for designing high-quality feasibility studies [53]. Although participant retention was $100 \%$, one participant (participant 7 ) did not adhere to the last 4-6 weeks of exercise due to medical reasons, and another participant (participant 3) had an acute shoulder trauma unrelated to the study. This may be one reason why only these two participants did not report improvement on GPE. The high retention 
Table 3 Primary outcomes in research progression criteria to inform the definitive randomised controlled trial

\begin{tabular}{lll}
\hline Research progression criteria & & Evaluation \\
\hline Participant recruitment rate $(n /$ month) & 5.6 & Amber (amend) \\
Completion of baseline outcome measures & & $105 \pm 9$ \\
Assessment duration including screening (min, mean \pm SD) & $12(100.0)$ & Green (go) \\
Participants answering acceptable duration $(n, \%)$ & $12(100.0)$ & Green (go) \\
Participant retention & $10(83.3)$ & Green (go) \\
Participants who completed the follow up $(n, \%)$ & $4(33.3)$ & Green (go) \\
Adherence to exercise intervention & 0 & Green (go) \\
Participants adhering to exercise programme $(n, \%)$ & 0 & Green (go) \\
Adverse events & Green (go) \\
Minor events $(n)$ &
\end{tabular}

These research progression criteria were based on a traffic light system of green (go), amber (amend) and red (stop) [24]

can be ascribed to high number of supervised sessions, where the physiotherapists motivated the participants to continue exercising, and that participants experienced the exercises as relevant and applicable for reducing their symptoms.

The duration of baseline and follow-up assessments was within the pre-defined, albeit arbitrary acceptable level of $120 \mathrm{~min}$, and according to participants' most included self-reported and objective measurements were relevant and covered important aspects of a thorough examination for their condition. To better reflect participant symptoms, which for one participant did not involve pain, NPRS could be extended to include NRS on symptoms (e.g. instability, subluxation, and laxity), and by adding the Patient Specific Functional Scale to contrast generic outcomes [54]. The shoulder flexion test (maximal passive flexion in supine) [51] and proprioception test at high range [48] were challenging to complete for participants with symptoms above $90^{\circ}$ of shoulder flexion, and the use of these tests should be reconsidered.

Current clinical recommendations for participants with HSD advice on consulting a physiotherapist, who

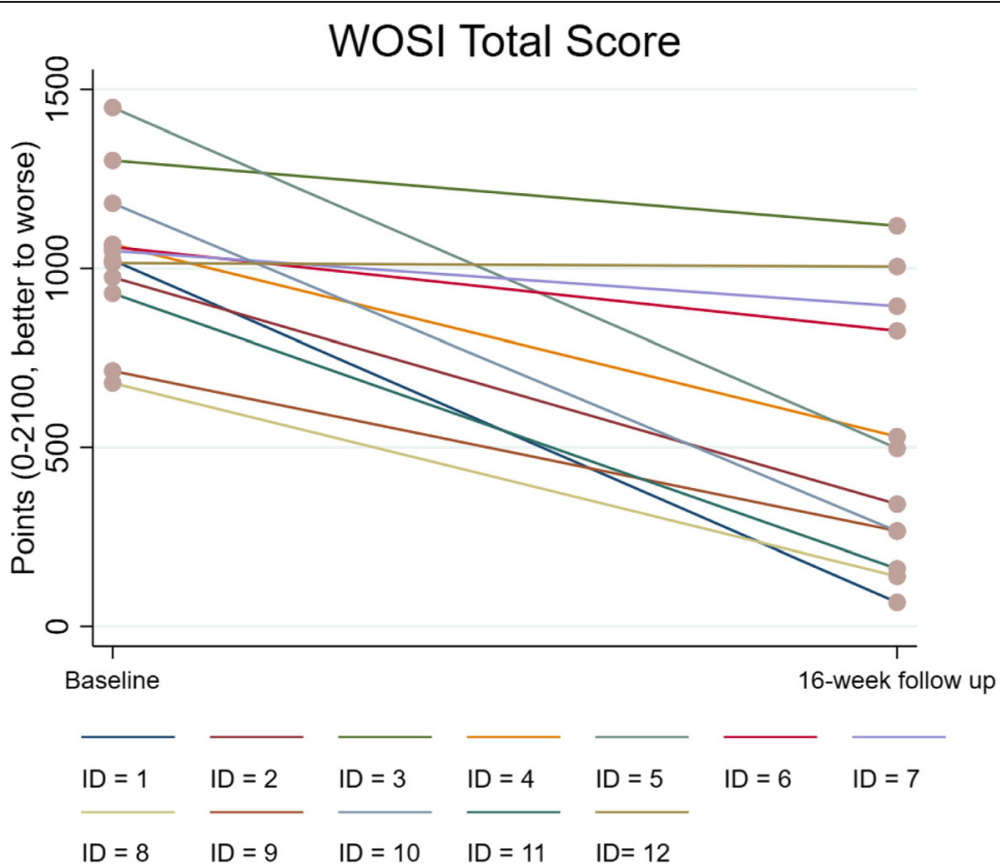

Fig. 3 The Western Ontario Shoulder Instability Index (WOSI) total score for every participant from baseline to follow up after 16 weeks of heavy shoulder strengthening exercise programme 
Table 4 Secondary treatment outcomes in participants with hypermobility spectrum disorder and long-lasting shoulder symptoms $(n=12)$

\begin{tabular}{|c|c|c|c|c|}
\hline & Baseline & Follow up & $\begin{array}{l}\text { Within-group mean change } \\
(95 \% \mathrm{Cl})\end{array}$ & $\begin{array}{l}\text { Within-group mean } \\
\% \text {-improvement }\end{array}$ \\
\hline \multicolumn{5}{|l|}{ Self-reported outcome measures } \\
\hline WOSI total score, $0-2100$ & $1037 \pm 215$ & $509 \pm 365$ & $-528(-738,-318)$ & 51 \\
\hline Physical symptoms, 0-1000 & $455 \pm 104$ & $211 \pm 151$ & $-245(-337,-152)$ & 54 \\
\hline Sports/recreation/work, 0-400 & $228 \pm 65$ & $112 \pm 97$ & $-117(-172,-61)$ & 51 \\
\hline Lifestyle, 0-400 & $151 \pm 94$ & $84 \pm 79$ & $-67(-113,-22)$ & 44 \\
\hline Emotions, 0-300 & $203 \pm 43$ & $103 \pm 72$ & $-100(-159,-40)$ & 49 \\
\hline \multicolumn{5}{|l|}{ Shoulder pain (NPRS) during the past 7 days } \\
\hline Lowest, 0-10 & $1.7 \pm 1.4$ & $0.8 \pm 1.1$ & $-0.9(-1.7,-0.2)$ & 53 \\
\hline Highest, 0-10 & $5.4 \pm 2.6$ & $2.9 \pm 2.3$ & $-2.5(-3.8,-1.2)$ & 46 \\
\hline Average, $0-10$ & $3.5 \pm 1.9$ & $1.1 \pm 1.2$ & $-2.4(-3.7,-1.2)$ & 69 \\
\hline CIS, fatigue subscale, 8-56 & $39 \pm 12$ & $30 \pm 11$ & $-9(-16,-2)$ & 23 \\
\hline COOP/WONCA, 6-30 & $14.3 \pm 3.7$ & $13.2 \pm 3.8$ & $-1.2(-4.5,2.1)$ & 8 \\
\hline Tampa Scale of Kinesiophobia, 11-44 & $25.5 \pm 4.4$ & $22.3 \pm 4.3$ & $-3.3(-5.7,-0.8)$ & 13 \\
\hline Global Perceived Effect, - 5 to 5 & - & $3.5[3-5]$ & - & - \\
\hline \multicolumn{5}{|l|}{ EQ-5D-3L Health status questionnaire } \\
\hline EQ-VAS, 0-100 & $68 \pm 17$ & $75 \pm 16$ & $7(-7,21)$ & 10 \\
\hline Index score, $<0-1$ & $0.80 \pm 0.10$ & $0.81 \pm 0.10$ & $0.01(-0.08,0.09)$ & 1 \\
\hline \multicolumn{5}{|l|}{ Objective outcome measures } \\
\hline \multicolumn{5}{|l|}{ Range of motion, ${ }^{\circ}$} \\
\hline Internal rotation passive & $66.4 \pm 18.8$ & $57.5 \pm 7.7$ & $-8.9(-18.8,0.9)$ & 13 \\
\hline Internal rotation active & $62.3 \pm 16.3$ & $58.7 \pm 8.2$ & $-3.5(-12.4,5.3)$ & 6 \\
\hline External rotation passive & $100.9 \pm 27.3$ & $100.9 \pm 17.0$ & $-0.1(-13.3,13.2)$ & 0 \\
\hline External rotation active & $101.7 \pm 22.3$ & $103.6 \pm 13.8$ & $1.9(-9.3,13.1)$ & -2 \\
\hline Total rotation test $>180^{\circ}$ & $5(42)$ & $1(8)$ & & \\
\hline \multicolumn{5}{|l|}{ Isometric shoulder strength, Nm/kg } \\
\hline Scaption $(n=11)$ & $1.67 \pm 0.72$ & $2.18 \pm 0.76$ & $0.51(0.23,0.78)$ & 31 \\
\hline Internal rotation $(n=11)$ & $4.57 \pm 1.71$ & $5.90 \pm 1.41$ & $1.32(0.70,1.95)$ & 29 \\
\hline External rotation $(n=11)$ & $3.17 \pm 1.22$ & $4.05 \pm 1.02$ & $0.89(0.37,1.40)$ & 28 \\
\hline External/internal rotation ratio $(n=11)$ & $0.72 \pm 0.17$ & $0.69 \pm 0.10$ & $-0.02(-0.10,0.05)$ & -3 \\
\hline \multicolumn{5}{|l|}{ Proprioception in flexion, error $\left(^{\circ}\right)$} \\
\hline Low range, $55^{\circ} \pm 10^{\circ}$ & $4.9 \pm 1.7$ & $3.6 \pm 1.4$ & $-1.2(-2.4,0.0)$ & 24 \\
\hline Mid-range, $90^{\circ} \pm 10^{\circ}$ & $4.3 \pm 2.0$ & $3.4 \pm 1.5$ & $-0.9(-2.2,0.3)$ & 21 \\
\hline High range, $125^{\circ} \pm 10^{\circ}(n=11)$ & $4.3 \pm 2.0$ & $4.9 \pm 3.2$ & $0.6(-2.0,3.2)$ & -14 \\
\hline \multicolumn{5}{|l|}{ Shoulder instability and laxity tests, positive, $n(\%)$} \\
\hline Shoulder flexion test & $1(8.3)$ & $2(16.7)$ & & \\
\hline Apprehension test & $6(50.0)$ & $4(33.3)$ & & \\
\hline Relocation test & $5(41.7)$ & $2(16.7)$ & & \\
\hline Release test & $4(33.3)$ & $2(16.7)$ & & \\
\hline Load and shift anterior (0-3), positive $2-3$ & $5(41.7)$ & $8(66.7)$ & & \\
\hline Load and shift posterior (0-3), positive 2-3 & $0(0.0)$ & $0(0.0)$ & & \\
\hline Sulcus sign, positive $>2 \mathrm{~cm}$ & $0(0.0)$ & $0(0.0)$ & & \\
\hline Gagey, positive $>105^{\circ}$ & $4(33.3)$ & $1(8.3)$ & & \\
\hline Rotés Queról, positive $>90^{\circ}$ & $4(33.3)$ & $0(0.0)$ & & \\
\hline
\end{tabular}

Data are presented as mean $\pm \mathrm{SD}$, median [IQR], and $n(\%)$

$S D$ standard deviation, IQR interquartile range, $C I$ confidence interval, WOSI Western Ontario Shoulder Instability Index, NPRS numeric pain rating scale, CIS Checklist Individual Strength, COOP/WONCA Dartmouth Primary Care Cooperative Research Network/World Organization of National Colleges, Academies and Academic Associations of General Practitioners/Family Physicians, EQ-5D-3L European Quality of life - 5 Dimensions - Three-Level, VAS visual analogue scale 
should prescribe exercises with low load, educate about the condition, and give advice on how to protect the joints in daily activities [13, 14, 55]. When choosing exercises for people with HSD, a general application among clinicians and researchers is to start with closed kinetic chain exercises in neutral to mid-range positions, and with no load or low loads applied to avoid excessive shear stress on the joint, before introducing more functional and full range open kinetic chain movements. Because these management considerations are contrary to the shoulder exercises offered in this study (mainly heavy load open kinetic chain movements in full range), it was imperative to register both minor adverse events and serious events in addition to exercise adherence to address potential threats to compliance. Adherence was high $(83 \%)$, and based on participant feedback, maintaining supervised sessions twice a week was important for their adherence because it allowed them to be confident in performing exercises correctly and safely, besides being able to apply exercise progressions under supervised settings. Further, no serious adverse events were reported, and the reported minor adverse events (soreness and/or pain flare-up) are considered as normal shortlasting responses to heavy strengthening exercises or even to exercise in general $[56,57]$. These findings support that the heavy strengthening exercise approach competes against the general understanding of how to prescribe exercise programmes for this population and could become an alternative and valuable treatment in people with HSD.

The rationale for applying heavy shoulder strengthening exercise in this population was to target the active elements that are involved in shoulder stability with the aim of impacting the cross-sectional areas of the muscles as well as the voluntary activation of the available muscle mass. Both factors would potentially in a 16-week perspective increase muscle strength and thereby the possibility to establish active support of the joint to compensate for the lack of passive joint stability in people with HSD. The observed strength improvements at 16-week follow up (without changing the ER/IR ratio) were plausibly mediated by improved neuromuscular function, primarily in the initial phase of the exercise programme, besides peripheral adaptations in the musculotendinous unit (e.g. hypertrophy and tendon stiffness $[19,20,58])$ of scapular muscles and rotator cuff muscles [30]. Muscle and tendon stiffness around the shoulder joint is difficult to examine but can be evaluated indirectly with clinical tests of shoulder laxity. Passive IR range of motion, shoulder total rotation $>180^{\circ}$, Gagey (inferior glenohumeral laxity), and Rotés Quérol $\left(E R>90^{\circ}\right)$ tests indicated clinically reduced shoulder laxity. Another potential mechanism is a better ability to protect the shoulder at end range due to an improved joint awareness, which can be partly supported by the observed improvement in proprioception (sense of the relative position of one's own parts of the body and strength of effort being employed in movement) measured at low range of shoulder flexion. Looking at the selfreported outcomes, participants improved above the minimal clinically important difference (MCID) in WOSI total score (51\%; MCID 10.4-14\% [59, 60]), which will be the primary outcome to evaluate the treatment effectiveness in the definitive RCT. Improvements were also observed in other relevant outcomes such as shoulder pain, kinesiophobia, and level of prolonged fatigue. Along with the questionnaires about general health status, these outcomes are important to assess when evaluating treatment effectiveness in a future RCT, and for comparison across other studies and patient populations. More in depth analyses of these secondary outcomes are outside the scope of this feasibility study, but the apparent potential benefits justify a more thorough evaluation in an RCT.

Based on the research progression criteria and findings in self-reported outcomes, objective outcome measures, and qualitative feedback, it seems feasible to proceed with an RCT if an improved recruitment strategy is applied. To ensure the inclusion of participants who are seeking professional help by their own initiative and with symptoms reaching a certain level of severity, we will involve more GPs and physiotherapy clinics in the recruitment process rather than recruiting via other channels (e.g. community advertising). Although only one out of 13 eligible participants declined to participate due to time constraints, this number is anticipated to increase in an RCT because a larger sample size is needed, why the number of people declining for various reasons will also increase, which is an incentive for improving recruitment to the absolute maximum. Another reason for declining to participate is the inherent barrier in the randomisation procedure which does not allow the participant to know their treatment in advance; however, the comparator group in the definitive RCT will receive a home-based exercise programme build on the current practice and clinical recommendations with (only) three supervised sessions, and as such this will probably not affect the recruitment rate considerably but could impair exercise adherence.

\section{Strengths and limitations}

The strengths of the study were the standardised, transparent, and precisely described exercise programme targeting scapular and rotator cuff muscles; careful training of involved physiotherapists and supervision of participants during exercise interventions; and the pre-defined progression and evaluation criteria. Due to the inherent design of a feasibility study, methodological limitations, such as lack of a control group and inability to ensure blinding of participants and the investigator, limit conclusions that can be drawn on the effectiveness of the 
exercise programme. The observed improvements in secondary outcomes could be in part due to regression to the mean. Therefore, the current study findings highlight the feasibility and safety required before testing heavy shoulder strengthening exercise in an RCT.

\section{Conclusions}

In conclusion, heavy shoulder strengthening exercise is feasible and safe for people with HSD and long-lasting shoulder symptoms for more than 3 months. A future $\mathrm{RCT}$, with an improved recruitment strategy, will demonstrate whether the exercise programme is also effective in improving symptoms and decreasing shoulder laxity/instability in this population.

\section{Supplementary information}

Supplementary information accompanies this paper at https://doi.org/10. 1186/s40814-020-00632-y.

\section{Additional file 1: CONSORT 2010 checklist of information to include} when reporting a pilot or feasibility trial

Additional file 2: The TIDieR (Template for Intervention Description and Replication) Checklist*: Information to include when describing an intervention and the location of the information

Additional file 3: Exercise intervention, CERT Checklist and mechanobiological description

Additional file 4: Self-reported outcomes

Additional file 5: Objective outcomes

\section{Abbreviations}

CIS: Checklist of Individual Strength; COOP/WONCA: Dartmouth Primary Care Cooperative Research Network/World Organization of National Colleges, Academies and Academic Associations of General Practitioners/Family Physicians; Cl: Confidence interval; EQ-5D-3L: European Quality of life - 5 Dimensions - Three-Level; ER: External rotation; GJH: Generalised joint hypermobility; GPE: Global Perceived Effectiveness; HSD: Hypermobility spectrum disorder; IQR: Interquartile range; IPAQ: International Physical Activity Questionnaire; IR: Internal rotation; MCID: Minimal clinically important difference; NPRS: Numerical pain rating scale; RCT: Randomised controlled trial; RM: Repetition maximum; SD: Standard deviation; TSK-11: Tampa Scale of Kinesiophobia-11; VAS: Visual analogue scale; WOSI: Western Ontario Shoulder Instability Index; 5PQ: 5-part questionnaire

\section{Acknowledgements}

The authors would like to acknowledge OPEN, Odense Patient data Explorative Network, Odense University Hospital, Odense, Denmark, and the involved participants, physiotherapists, and general practitioners for their contributions to this study.

\section{Authors' contributions}

Concept/idea/research design: all authors. Acquisition of data: BL. Analysis and interpretation of data: all authors. Writing/review/editing of manuscript: all authors. Final approval of the manuscript: all authors. Acquisition of funding: $B L$ and BJK. Providing participants: BL and JS

\section{Funding}

This work was supported by the Region of Southern Denmark, Esbjerg municipality, The Danish Rheumatism association, Fund for Research, Quality and Education in Physiotherapy Practice, and the University of Southern Denmark, all in Denmark. STS is currently funded by a grant from Region Zealand in Denmark (Exercise First) and a grant from the European Research Council (ERC) under the European Union's Horizon 2020 research and innovation program (grant agreement No 801790).

The funders were not involved in any part of the research project.
Availability of data and materials

The datasets generated and/or analysed during the current study are available from the corresponding author on reasonable request.

\section{Ethics approval and consent to participate}

This study was approved by the Regional Committees on Health Research Ethics for Southern Denmark (S-20170066). A written informed consent was obtained before enrolment of participants, and the rights of participants were protected.

\section{Consent for publication}

Written consent for publication of images in Fig. 1 was obtained.

\section{Competing interests}

STS reports personal fees from the Journal of Orthopaedic \& Sports Physical Therapy, grants from The Lundbeck Foundation, personal fees from Munksgaard, outside the submitted work; and being a co-founder of GLA:D. GLA:D is a non-profit initiative hosted at the University of Southern Denmark aimed at implementing clinical guidelines for osteoarthritis in clinical practice. JS reports grants from Astra-zeneca, outside the submitted work. BL, UJ, KS and BJK have nothing to disclose.

\section{Author details}

${ }^{1}$ Research Unit for Musculoskeletal Function and Physiotherapy, Department of Sports Science and Clinical Biomechanics, University of Southern Denmark, Odense, Denmark. ${ }^{2}$ Department of Physiotherapy and Occupational Therapy, Næstved-Slagelse-Ringsted Hospitals, Slagelse, Denmark. ${ }^{3}$ Orthopedic Research Unit, Odense University Hospital, University of Southern Denmark, Odense, Denmark. ${ }^{4}$ Research Unit of General Practice, Faculty of Health Science, University of Southern Denmark, Odense, Denmark. ${ }^{5}$ Research Unit of Physical Activity and Health in Work Life, Department of Sports Science and Clinical Biomechanics, University of Southern Denmark, Odense, Denmark. ${ }^{6}$ Department of Clinical Research, University of Southern Denmark, Odense, Denmark.

Received: 21 May 2019 Accepted: 12 June 2020

Published online: 15 August 2020

\section{References}

1. Hakim A, Grahame R. Joint hypermobility. Best Pract Res Clin Rheumatol. 2003;17(6):989-1004.

2. Singh H, McKay M, Baldwin J, Nicholson L, Chan C, Burns J, Hiller CE. Beighton scores and cut-offs across the lifespan: cross-sectional study of an Australian population. Rheumatology (Oxford). 2017;56(11):1857-64.

3. Remvig L, Jensen DV, Ward RC. Epidemiology of general joint hypermobility and basis for the proposed criteria for benign joint hypermobility syndrome: review of the literature. J Rheumatol. 2007:34(4):804-9.

4. Johnson SM, Robinson CM. Shoulder instability in patients with joint hyperlaxity. J Bone Joint Surg Am. 2010;92(6):1545-57.

5. Johannessen EC, Reiten HS, Lovaas H, Maeland S, Juul-Kristensen B. Shoulder function, pain and health related quality of life in adults with joint hypermobility syndrome/Ehlers-Danlos syndrome-hypermobility type. Disabil Rehabil. 2016;38(14):1382-90.

6. Rombaut L, Malfait F, Cools A, De Paepe A, Calders P. Musculoskeletal complaints, physical activity and health-related quality of life among patients with the Ehlers-Danlos syndrome hypermobility type. Disabil Rehabil. 2010;32(16):1339-45.

7. Liaghat B, Juul-Kristensen B, Frydendal T, Marie Larsen C, Sogaard K, Illka Tapio Salo A. Competitive swimmers with hypermobility have strength and fatigue deficits in shoulder medial rotation. J Electromyogr Kinesiol. 2018;39:1-7.

8. Cameron KL, Duffey ML, DeBerardino TM, Stoneman PD, Jones CJ, Owens BD. Association of generalized joint hypermobility with a history of glenohumeral joint instability. J Athl Train. 2010;45(3):253-8.

9. Chahal J, Leiter J, McKee MD, Whelan DB. Generalized ligamentous laxity as a predisposing factor for primary traumatic anterior shoulder dislocation. J Shoulder Elbow Surg. 2010;19(8):1238-42.

10. Saremi H, Yavarikia A, Jafari N. Generalized ligamentous laxity: an important predisposing factor for shoulder injuries in athletes. Iran Red Crescent Med J. 2016;18(6):e38903. 
11. Castori M, Tinkle B, Levy H, Grahame R, Malfait F, Hakim A. A framework for the classification of joint hypermobility and related conditions. Am J Med Genet C Semin Med Genet. 2017;175(1):148-57.

12. Juul-Kristensen B, Ostengaard L, Hansen S, Boyle E, Junge T, Hestbaek L. Generalised joint hypermobility and shoulder joint hypermobility, - risk of upper body musculoskeletal symptoms and reduced quality of life in the general population. BMC Musculoskelet Disord. 2017;18(1):226.

13. The Danish Rheumatism Association. Treatment of hypermobility - prevention of pain and injuries https:/www.gigtforeningen.dk/viden-om-gigt/diagnoser/ hypermobilitet/behandling-af-hypermobilitet/. Accessed 29 May 2020.

14. Arthritis Research UK. Joint hypermobility 2015. Available from: https://www. versusarthritis.org/media/1255/joint-hypermobility-information-booklet.pdf

15. Smith TO, Bacon H, Jerman E, Easton V, Armon K, Poland F, Macgregor AJ. Physiotherapy and occupational therapy interventions for people with benign joint hypermobility syndrome: a systematic review of clinical trials. Disabil Rehabil. 2014;36(10):797-803.

16. Scheper MC, Juul-Kristensen B, Rombaut L, Rameckers EA, Verbunt J, Engelbert RH. Disability in adolescents and adults diagnosed with hypermobility-related disorders: a meta-analysis. Arch Phys Med Rehabil. 2016;97(12):2174-87

17. Palmer S, Bailey S, Barker L, Barney L, Elliott A. The effectiveness of therapeutic exercise for joint hypermobility syndrome: a systematic review. Physiotherapy. 2014;100(3):220-7.

18. Warby SA, Pizzari T, Ford JJ, Hahne AJ, Watson L. The effect of exercisebased management for multidirectional instability of the glenohumeral joint: a systematic review. J Shoulder Elbow Surg. 2014;23(1):128-42.

19. Laudner KG, Metz B, Thomas DQ. Anterior glenohumeral laxity and stiffness after a shoulder-strengthening program in collegiate cheerleaders. J Athl Train. 2013;48(1):25-30

20. Couppe C, Kongsgaard M, Aagaard P, Hansen P, Bojsen-Moller J, Kjaer M, Magnusson SP, et al. J Appl Physiol (1985). 2008;105(3):805-10.

21. Rombaut L, Malfait F, De Wandele I, Mahieu N, Thijs Y, Segers P, De Paepe A, Calders P. Muscle-tendon tissue properties in the hypermobility type of Ehlers-Danlos syndrome. Arthritis Care Res (Hoboken). 2012;64(5):766-72.

22. Moller MB, Kjaer M, Svensson RB, Andersen JL, Magnusson SP, Nielsen RH. Functional adaptation of tendon and skeletal muscle to resistance training in three patients with genetically verified classic Ehlers Danlos Syndrome. Muscles Ligaments Tendons J. 2014;4(3):315-23.

23. Eldridge SM, Chan CL, Campbell MJ, Bond CM, Hopewell S, Thabane L, Lancaster GA, group PC. CONSORT 2010 statement: extension to randomised pilot and feasibility trials. Pilot Feasibility Stud. 2016;2:64.

24. Avery KN, Williamson PR, Gamble C, O'Connell Francischetto E, Metcalfe C, Davidson P, Williams H, Blazeby JM, members of the Internal Pilot Trials Workshop supported by the Hubs for Trials Methodology R. Informing efficient randomised controlled trials: exploration of challenges in developing progression criteria for internal pilot studies. BMJ Open. 2017; 7(2):e013537.

25. Malfait F, Francomano C, Byers P, Belmont J, Berglund B, Black J, Bloom L, Bowen JM, Brady AF, Burrows NP, Castori M, Cohen H, Colombi M, Demirdas S, De Backer J, De Paepe A, Fournel-Gigleux S, Frank M, Ghali N, Giunta C, et al. The 2017 international classification of the Ehlers-Danlos syndromes. Am J Med Genet C Semin Med Genet. 2017;175(1):8-26.

26. Hakim AJ, Grahame R. A simple questionnaire to detect hypermobility: an adjunct to the assessment of patients with diffuse musculoskeletal pain. Int J Clin Pract. 2003;57(3):163-6.

27. Harris PA, Taylor R, Thielke R, Payne J, Gonzalez N, Conde JG. Research electronic data capture (REDCap)--a metadata-driven methodology and workflow process for providing translational research informatics support. $J$ Biomed Inform. 2009;42(2):377-81.

28. Hoffmann TC, Glasziou PP, Boutron I, Milne R, Perera R, Moher D, Altman DG, Barbour V, Macdonald H, Johnston M, Lamb SE, Dixon-Woods M, McCulloch P, Wyatt JC, Chan A-W, Michie S. Better reporting of interventions: template for intervention description and replication (TIDieR) checklist and guide. BMJ: British Medical Journal. 2014;348:g1687.

29. Slade SC, Dionne CE, Underwood M, Buchbinder R. Consensus on Exercise Reporting Template (CERT): explanation and elaboration statement. Br J Sports Med. 2016

30. Toigo M, Boutellier U. New fundamental resistance exercise determinants of molecular and cellular muscle adaptations. Eur J Appl Physiol. 2006;97(6):643-63.
31. Brzycki M. Strength testing — predicting a one-rep max from reps-to-fatigue. Journal of Physical Education, Recreation \& Dance. 1993;64(1):88-90.

32. American College of Sports Medicine. ACSM's guidelines for exercise testing and prescription. 10th Edition ed. Philadelphia, United States Lippincott Williams and Wilkins 2017.

33. McClure P, Tate AR, Kareha S, Irwin D, Zlupko E. A clinical method for identifying scapular dyskinesis, part 1: reliability. Journal of athletic training 2009;44(2):160-4.

34. Warby SA, Ford JJ, Hahne AJ, Watson L, Balster S, Lenssen R, Pizzari T. Comparison of 2 exercise rehabilitation programs for multidirectional instability of the glenohumeral joint: a randomized controlled trial. Am J Sports Med. 2018;46(1):87-97.

35. Watson L, Balster S, Lenssen R, Hoy G, Pizzari T. The effects of a conservative rehabilitation program for multidirectional instability of the shoulder. J Shoulder Elbow Surg. 2018;27(1):104-11.

36. U.S Food and Drug Administration. What is a serious adverse event? https:// www.fda.gov/safety/medwatch/howtoreport/ucm053087.htm. Accessed 21 May 2019.

37. Eshoj H, Bak K, Blond L, Juul-Kristensen B. Translation, adaptation and measurement properties of an electronic version of the Danish Western Ontario Shoulder Instability Index (WOSI). BMJ Open. 2017;7(7):e014053.

38. Breivik H, Borchgrevink PC, Allen SM, Rosseland LA, Romundstad L, Hals EK, Kvarstein G, Stubhaug A. Assessment of pain. Br J Anaesth. 2008;101(1):17-24.

39. Voermans NC, Knoop H. Both pain and fatigue are important possible determinants of disability in patients with the Ehlers-Danlos syndrome hypermobility type. Disabil Rehabil. 2011;33(8):706-7.

40. Bentsen BG, Natvig B, Winnem M. Questions you didn't ask? COOP/WONCA Charts in clinical work and research. World Organization of Colleges, Academies and Academic Associations of General Practitioners/Family Physicists. Fam Pract. 1999;16(2):190-5.

41. Kinnersley $P$, Peters T, Stott N. Measuring functional health status in primary care using the COOP-WONCA charts: acceptability, range of scores, construct validity, reliability and sensitivity to change. Br J Gen Pract. 1994; 44(389):545-9.

42. Mintken PE, Cleland JA, Whitman JM, George SZ. Psychometric properties of the Fear-Avoidance Beliefs Questionnaire and Tampa Scale of Kinesiophobia in patients with shoulder pain. Arch Phys Med Rehabil. 2010;91(7):1128-36.

43. Kamper SJ, Ostelo RW, Knol DL, Maher CG, de Vet HC, Hancock MJ. Global Perceived Effect scales provided reliable assessments of health transition in people with musculoskeletal disorders, but ratings are strongly influenced by current status. J Clin Epidemiol. 2010;63(7):760-6 e1.

44. Forouzanfar $T$, Weber WE, Kemler M, van Kleef $M$. What is a meaningful pain reduction in patients with complex regional pain syndrome type 1? Clin J Pain. 2003:19(5):281-5.

45. Janssen MF, Pickard AS, Golicki D, Gudex C, Niewada M, Scalone L, Swinburn P, Busschbach J. Measurement properties of the EQ-5D-5L compared to the EQ-5D-3L across eight patient groups: a multi-country study. Qual Life Res. 2013;22(7):1717-27.

46. Ingwersen $\mathrm{KG}$, Christensen $\mathrm{R}$, Sorensen $\mathrm{L}$, Jorgensen HR, Jensen $\mathrm{SL}$, Rasmussen $\mathrm{S}$, Sogaard K, Juul-Kristensen B. Progressive high-load strength training compared with general low-load exercises in patients with rotator cuff tendinopathy: study protocol for a randomised controlled trial. Trials. 2015;16:27.

47. Clarsen B, Bahr R, Andersson SH, Munk R, Myklebust G. Reduced glenohumeral rotation, external rotation weakness and scapular dyskinesis are risk factors for shoulder injuries among elite male handball players: a prospective cohort study. Br J Sports Med. 2014;48(17):1327-33.

48. Vafadar AK, Cote JN, Archambault PS. Interrater and intrarater reliability and validity of 3 measurement methods for shoulder-position sense. J Sport Rehabil. 2016;Technical Report 19:2014-0309.

49. Eshoj H, Ingwersen KG, Larsen CM, Kjaer BH, Juul-Kristensen B. Intertester reliability of clinical shoulder instability and laxity tests in subjects with and without self-reported shoulder problems. BMJ Open. 2018;8(3):e018472.

50. Juul-Kristensen B, Rogind H, Jensen DV, Remvig L. Inter-examiner reproducibility of tests and criteria for generalized joint hypermobility and benign joint hypermobility syndrome. Rheumatology (Oxford). 2007;46(12): 1835-41.

51. Nicholson LL, Chan C. The Upper Limb Hypermobility Assessment Tool: a novel validated measure of adult joint mobility. Musculoskeletal Science and Practice. 2018

52. Julious SA. Sample size of 12 per group rule of thumb for a pilot study. Pharmaceut Statist. 2005:4:287-91. 
53. Eldridge SM, Lancaster GA, Campbell MJ, Thabane L, Hopewell S, Coleman $\mathrm{CL}$, Bond CM. Defining feasibility and pilot studies in preparation for randomised controlled trials: development of a conceptual framework. PLoS One. 2016;11(3):e0150205.

54. Donnelly C, Carswell A. Individualized outcome measures: a review of the literature. Can J Occup Ther. 2002;69(2):84-94.

55. Engelbert RH, Juul-Kristensen B, Pacey V, de Wandele I, Smeenk S, Woinarosky N, Sabo S, Scheper MC, Russek L, Simmonds JV. The evidence-based rationale for physical therapy treatment of children, adolescents, and adults diagnosed with joint hypermobility syndrome/hypermobile Ehlers Danlos syndrome. Am J Med Genet C Semin Med Genet. 2017;175(1):158-67.

56. Sandal LF, Roos EM, Bogesvang SJ, Thorlund JB. Pain trajectory and exerciseinduced pain flares during 8 weeks of neuromuscular exercise in individuals with knee and hip pain. Osteoarthritis Cartilage. 2016;24(4):589-92.

57. Cheung K, Hume P, Maxwell L. Delayed onset muscle soreness : treatment strategies and performance factors. Sports Med. 2003;33(2):145-64.

58. Kongsgaard M, Reitelseder S, Pedersen TG, Holm L, Aagaard P, Kjaer M, Magnusson SP. Region specific patellar tendon hypertrophy in humans following resistance training. Acta Physiol (Oxf). 2007;191(2):111-21.

59. van der Linde JA, van Kampen DA, van Beers L, van Deurzen DFP, Saris DBF, Terwee $\mathrm{CB}$. The responsiveness and minimal important change of the Western Ontario Shoulder Instability Index and Oxford Shoulder Instability Score. J Orthop Sports Phys Ther. 2017;47(6):402-10.

60. Kirkley A, Werstine R, Ratjek A, Griffin S. Prospective randomized clinical trial comparing the effectiveness of immediate arthroscopic stabilization versus immobilization and rehabilitation in first traumatic anterior dislocations of the shoulder: long-term evaluation. Arthroscopy. 2005;21(1):55-63.

\section{Publisher's Note}

Springer Nature remains neutral with regard to jurisdictional claims in published maps and institutional affiliations.

Ready to submit your research? Choose BMC and benefit from:

- fast, convenient online submission

- thorough peer review by experienced researchers in your field

- rapid publication on acceptance

- support for research data, including large and complex data types

- gold Open Access which fosters wider collaboration and increased citations

- maximum visibility for your research: over $100 \mathrm{M}$ website views per year

At $\mathrm{BMC}$, research is always in progress.

Learn more biomedcentral.com/submissions 